\title{
Antifungal prophylaxis with posaconazole vs. fluconazole or itraconazole in pediatric patients with neutropenia
}

\author{
M. Döring • M. Eikemeier • K. M. Cabanillas Stanchi • \\ U. Hartmann • M. Ebinger • C.-P. Schwarze • A. Schulz • \\ R. Handgretinger $\cdot$ I. Müller
}

Received: 20 November 2014 / Accepted: 26 January 2015 / Published online: 14 February 2015

(C) The Author(s) 2015. This article is published with open access at Springerlink.com

\begin{abstract}
Pediatric patients with hemato-oncological malignancies and neutropenia resulting from chemotherapy have a high risk of acquiring invasive fungal infections. Oral antifungal prophylaxis with azoles, such as fluconazole or itraconazole, is preferentially used in pediatric patients after chemotherapy.
\end{abstract}

M. Döring $(\bowtie) \cdot$ K. M. Cabanillas Stanchi • M. Ebinger •

C.-P. Schwarze $\cdot$ R. Handgretinger

Department I- General Paediatrics, Hematology/Oncology,

University Hospital Tuebingen, Children's Hospital,

Hoppe-Seyler-Str. 1, 72076 Tuebingen, Germany

e-mail: michaela.doering@med.uni-tuebingen.de

K. M. Cabanillas Stanchi

e-mail: karin.cabanillas@med.uni-tuebingen.de

M. Ebinger

e-mail: martin.ebinger@med.uni-tuebingen.de

C.-P. Schwarze

e-mail: carl-philipp.schwarze@med.uni-tuebingen.de

R. Handgretinger

e-mail: rupert.handgretinger@med.uni-tuebingen.de

M. Eikemeier · A. Schulz

Department of Pediatric Hematology and Oncology,

University Hospital Ulm, Children's Hospital,

Albert-Einstein-Allee 23, 89081 Ulm, Germany

M. Eikemeier

e-mail: melinda.eikemeier@gmx.de

A. Schulz

e-mail: ansgar.schulz@uniklinik-ulm.de

U. Hartmann

Pharmacy, University Hospital Tuebingen, Children's Hospital,

Hoppe-Seyler-Str. 1, 72076 Tuebingen, Germany

e-mail: ulrike.hartmann@med.uni-tuebingen.de

I. Müller

Clinic of Pediatric Hematology and Oncology, University Medical

Center Hamburg-Eppendorf, Martinistr. 52,

20246 Hamburg, Germany

e-mail: i.mueller@uke.de
During this retrospective analysis, posaconazole was administered based on favorable results from studies in adult patients with neutropenia and after allogeneic hematopoietic stem cell transplantation. Retrospectively, safety, feasibility, and initial data on the efficacy of posaconazole were compared to fluconazole and itraconazole in pediatric and adolescent patients during neutropenia. Ninety-three pediatric patients with hemato-oncological malignancies with a median age of 12 years (range 9 months to 17.7 years) that had prolonged neutropenia ( $>5$ days) after chemotherapy or due to their underlying disease, and who received fluconazole, itraconazole, or posaconazole as antifungal prophylaxis, were analyzed in this retrospective single-center survey. The incidence of invasive fungal infections in pediatric patients was low under each of the azoles. One case of proven aspergillosis occurred in each group. In addition, there were a few cases of possible invasive fungal infection under fluconazole $(n=1)$ and itraconazole $(n=2)$. However, no such cases were observed under posaconazole. The rates of potentially clinical drug-related adverse events were higher in the fluconazole $(n=4)$ and itraconazole $(n=5)$ groups compared to patients receiving posaconazole $(n=3)$. Posaconazole, fluconazole, and itraconazole are comparably effective in preventing invasive fungal infections in pediatric patients. Defining dose recommendations in these patients requires larger studies.

Abbreviations
HSCT
ALL
ALT
AML
ANOVA
AP
AST
CT

Hematopoietic stem cell transplantation Acute lymphoblastic leukemia Alanine aminotransferase Acute myeloid leukemia Analysis of variance Alkaline phosphatase Aspartate aminotransferase Computed tomography 
EORTC/MSG European Organization for Research and Treatment of Cancer/Allergy and Infectious Diseases Mycoses Study Group

$\begin{array}{ll}\mathrm{GvHD} & \text { Graft-versus-host disease } \\ \mathrm{h} & \text { Hour(s) } \\ \mathrm{MDS} & \text { Myelodysplastic syndromes } \\ \mathrm{mg} / \mathrm{dL} & \text { Milligrams per deciliter } \\ \mathrm{mg} \mathrm{kg} \mathrm{BW} & -1 \mathrm{~d}^{-1} \\ & \text { Milligrams per kilogram of body weight } \\ & \text { per day } \\ \mathrm{mmol} / \mathrm{L} & \text { Millimol per liter } \\ \mathrm{NHL} & \text { Non-Hodgkin lymphoma } \\ \mathrm{U} / \mathrm{L} & \text { Units per liter }\end{array}$

\section{Introduction}

Invasive fungal infections belong to the most severe complications in patients with hemato-oncological malignancies during neutropenia after intensive chemotherapy, representing a leading cause for infectious mortality and morbidity in immunocompromised children. Immunocompromised pediatric patients with prolonged severe neutropenia resulting from highdose chemotherapy have a high risk of acquiring invasive fungal infections, especially with Aspergillus spp. and Candida spp., so that a systemic antifungal prophylaxis is indicated [1-5]. Immunosuppression and high-dose steroids are additional risk factors for fungal infections [6]. Oral antifungal prophylaxis with other azoles, fluconazole, itraconazole, and voriconazole is preferentially used in pediatric patients after chemotherapy. However, only a few studies have been published on pediatric patients with hematooncological malignancies, while antifungal prophylaxis seems well described for adult patients [7-13]. Fluconazole shows particularly good efficacy against Candida infections but not with Aspergillus spp. [14-17]. Itraconazole has a broader range of efficacy in comparison to fluconazole, which includes Aspergillus spp. and other rare mold infections [18-20]. In pediatric patients with neutropenia after chemotherapy and hematopoietic stem cell transplantation (HSCT) who received fluconazole and itraconazole, fungal breakthrough infections occurred time and again [16, 21-25]. In the hospital where the present analysis was performed, the administration of fluconazole and itraconazole in pediatric patients with neutropenia after high-dose chemotherapy and HSCT was associated with isolated cases of breakthrough infections. Due to the favorable results of antifungal prophylaxis with the broad-spectrum triazole posaconazole in adults experiencing prolonged neutropenia or patients with graftversus-host disease (GvHD) [11, 12, 26], the oral antifungal prophylaxis in pediatric patients after allogeneic HSCT was changed to posaconazole in 2007. During the present survey, the convincing results of these clinical studies in adults were also seen in the first 60 pediatric patients $(<12$ years of age), who received antifungal prophylaxis with posaconazole after allogeneic HSCT, regarding efficacy, safety, and feasibility [27]. This prompted another comparative analysis of three azoles as antifungal prophylaxis; itraconazole, voriconazole, and posaconazole. The retrospective analysis incorporated 150 immunocompromised pediatric patients after allogeneic HSCT and evaluated the comparable efficacy of these three azoles as antifungal prophylaxis [28].

Due to the excellent data from stem cell transplanted pediatric patients, the antifungal prophylaxis in pediatric patients after chemotherapy who experienced an anticipated prolonged neutropenia of at least 5 days was changed as well. Retrospectively, safety, feasibility, and initial data on the efficacy of posaconazole were compared with those of fluconazole and itraconazole in 93 pediatric patients and adolescents during the period of neutropenia after chemotherapy or during neutropenia caused by an underlying disease.

\section{Materials and methods}

\section{Survey design}

This analysis is a single-center, retrospective, non-randomized survey of 93 pediatric patients who received fluconazole, itraconazole, or posaconazole as oral antifungal monoprophylaxis during the phase of intensive induction, consolidation and re-induction chemotherapy, or during the period of neutropenia caused by an underlying disease. The survey was performed at the Department of Pediatric Hematology and Oncology, University Children's Hospital Tuebingen, Germany. The patient cohorts consisted of pediatric patients and adolescents with hemato-oncological malignancies, starting chemotherapy between January 2006 and January 2013 (Table 1). The analysis included only pediatric patients who were diagnosed with prolonged neutropenia (neutrophil counts $<500 / \mu \mathrm{L} ;>5$ days) when receiving antifungal prophylaxis. Antifungal monoprophylaxis with one of the three azoles began $24 \mathrm{~h}$ after the end of the chemotherapy cycle in pediatric patients with high-risk acute lymphoblastic leukemia (ALL), ALL relapse, acute myeloid leukemia (AML), AML relapse, non-Hodgkin lymphoma (NHL), Hodgkin lymphoma, osteosarcoma, Ewing sarcoma, and solid tumors, and ended at a minimum of one day before the start of chemotherapy. The treatment period was defined as the days when antifungal prophylaxis was orally administered with one of the three azoles. Pediatric patients with thalassemia major, aplastic anemia, or granulocytopenia were given antifungal monoprophylaxis during the whole period of neutropenia. Thirty-one of the 93 pediatric patients received antifungal 
Table 1 Patient characteristics

$A L L$ acute lymphoblastic leukemia; $A M L$ acute myeloid leukemia; $M D S$ myelodysplastic syndromes; $N H L$ non-Hodgkin lymphoma

Statistical tests: " $k$ proportions test" with XLSTAT 2013 or Chisquare test/Fisher's exact test on contingency tables

\begin{tabular}{llll}
\hline Characteristic & $\begin{array}{l}\text { Fluconazole } \\
(n=31)\end{array}$ & $\begin{array}{l}\text { Itraconazole } \\
(n=32)\end{array}$ & $\begin{array}{l}\text { Posaconazole } \\
(n=30)\end{array}$
\end{tabular}

Gender

Male

Female

$21(67.7)$

14 (43.8)

$12(40.0)$

0.089

Age group

$<6$ years

$10(32.3)$

$18(56.3)$

$18(60.0)$

(Chi-square)

$7-11$ years

$8(25.8)$

12 to $<18$ years

$4(12.9)$

7 (21.9)

$9(30.0)$

$8(25.0)$

$9(30.0)$

0.426

Diagnosis

ALL

$19(61.3)$

17 (53.1)

$12(40.0)$

(Chi-square)

ALL relapse

14 (45.2)

6 (18.8)

4 (13.3)

0.009

7 (21.9)

9 (30.0)

0.018

AML

$2(6.5)$

AML relapse

$0(0.0)$

$12(37.5)$

1 (3.3)

0.0003

$3(9.4)$

$0(0.0)$

1 (3.1)

NHL

$0(0.0)$

6 (19.4)

3 (10.0)

0.215

1 (3.3)

0.346

$3(10.0)$

0.114

Hodgkin lymphoma

$3(9.7)$

Thalassemia major

$0(0.0)$

$1(3.1)$

$0(0.0)$

$0(0.0)$

0.163

0.346
$0(0.0)$

Aplastic anemia

$0(0.0)$

Granulocytopenia

$0(0.0)$

Osteosarcoma

4 (12.9)

Ewing sarcoma

1 (3.2)

Solid tumor

$0(0.0)$

$0(0.0)$

$1(3.1)$

$1(3.1)$

$0(0.0)$

0.004

0.346

0.065

0.614

0.117

Systemic corticosteroids in $\mathrm{mg} \mathrm{kg} \mathrm{BW}^{-1} \mathrm{~d}^{-1}$

Dexamethasone

$0(0.0)$

$<2.0$ but $\geq 1.0$

$0(0.0)$

$<1.0$ but $\geq 0.5$

$9(29.0)$

$<0.5$

8 (25.8)

Prednisone/prednisolone

$\geq 2.0$

4 (12.9)

4 (12.9)

$0(0.0)$

$0(0.0)$

$<1.0$ but $\geq 0.5$

$0(0.0)$

$0(0.0)$

$0(0.0)$

$0(0.0)$

$5(16.7)$

1 (3.3)

$0(0.0)$

$0(0.0)$

2 (6.7)

0.708

$$
0(0.0)
$$

$0(0.0)$

$0(0.0$

$1(3.3)$

10 (31.3)

8 (26.7)

5 (16.7)

$1(3.3)$

1 (3.3)

2 (6.7)

$1(3.3)$

Methylprednisolone

$\geq 2.0$

$0(0.0)$

0.961

$1(3.1)$

$0(0.0)$

$0(0.0)$

$0(0.0)$

$0(0.0)$

$0(0.0)$

$0(0.0)$

\begin{tabular}{ll} 
& $k$ proportions test \\
$2(6.7)$ & 0.117 \\
$1(3.3)$ & 0.346 \\
$0(0.0)$ & 1 \\
$0(0.0)$ & 1 \\
\hline
\end{tabular}

prophylaxis with fluconazole at a dosage of $1 \times 5 \mathrm{mg}$ per kilogram of body weight per day $\left(\mathrm{mg} \mathrm{kg} \mathrm{BW}{ }^{-1} \mathrm{~d}^{-1}\right.$ ) (maximum $1 \times 400 \mathrm{mg} /$ day), while 32 were given antifungal prophylaxis with itraconazole at a dosage of $2 \times 5 \mathrm{mg} \mathrm{kg} \mathrm{BW}^{-1} \mathrm{~d}^{-1}$ (maximum $2 \times 200 \mathrm{mg} /$ day). Thirty other pediatric patients received antifungal prophylaxis with posaconazole $3 \times 4 \mathrm{mg} \mathrm{kg}$ $\mathrm{BW}^{-1} \mathrm{~d}^{-1}$ (maximum $3 \times 200 \mathrm{mg} /$ day). The primary objectives of this survey were to analyze the safety, feasibility, and efficacy of antifungal monoprophylaxis with fluconazole, itraconazole, or posaconazole for pediatric patients with hemato-oncological malignancies and neutropenia resulting from chemotherapy. The secondary objectives were to assess the incidence of invasive fungal infection with Aspergillus spp., Candida spp., or other fungal species. The observation period was defined as the time during the whole chemotherapy, including chemotherapy cycles. It started one day before the beginning of antifungal prophylaxis with one of the three azoles and ended three weeks after the last dosing or until the 
occurrence of a proven or probable fungal infection. For some pediatric patients, the observation period continued until shortly before the start of the conditioning regimen of the planned stem cell transplantation. The treatment period comprises days on which an antifungal monoprophylaxis with one of the three azoles, fluconazole, itraconazole, or posaconazole, was administered. The patients received fluconazole from 2006 to 2011, itraconazole from 2006 to 2012, and posaconazole from 2008 to 2013.

\section{Assessment of safety and tolerance}

For all of the 93 pediatric patients included in this survey, adverse events during the observation period and caused by one of the three azoles were graded according to the current United States National Cancer Institute's Common Terminology Criteria for Adverse Events [29]. During the observation period, an analysis of liver and kidney parameters, as well as electrolytes, was performed. The analysis of hepatic toxicity included transaminases alanine aminotransferase (ALT, normal range $\leq 39 \mathrm{U} / \mathrm{L}$ ) and aspartate aminotransferase (AST, normal range $\leq 39 \mathrm{U} / \mathrm{L}$ ), cholestasis parameters total bilirubin (normal range $\leq 1.1 \mathrm{mg} / \mathrm{dL}$ ) and direct bilirubin (normal range $\leq 0.3 \mathrm{mg} / \mathrm{dL}$ ), and alkaline phosphatase (AP, normal range $\leq 320 \mathrm{U} / \mathrm{L}$ ). The evaluation of kidney toxicity involved the examination of serum creatinine (normal range $\leq 0.7 \mathrm{mg} / \mathrm{dL}$ ) and urea (normal range $\leq 46 \mathrm{mg} / \mathrm{dL}$ ). In addition, an analysis of electrolytes potassium (normal range $\geq 3.4 \mathrm{mmol} / \mathrm{L}$ ), calcium (normal range $\geq 2.0 \mathrm{mmol} / \mathrm{L}$ ), and phosphate (normal range 1.1$1.5 \mathrm{mmol} / \mathrm{L}$ ) was carried out. We assessed clinically relevant elevations of $>1.5$ and $>2.5$ times the normal values of hepatic and renal parameters, and a decrease of potassium values $<3.4 \mathrm{mmol} / \mathrm{L}$ or $<2.4 \mathrm{mmol} / \mathrm{L}$, calcium values $<2.0 \mathrm{mmol} / \mathrm{L}$ or $<1.8 \mathrm{mmol} / \mathrm{L}$, and phosphate values $<1.1 \mathrm{mmol} / \mathrm{L}$ or $<0.8 \mathrm{mmol} / \mathrm{L}$. During the antifungal monoprophylaxis with one of the three azoles, fluconazole, itraconazole, or posaconazole, analysis of blood cell counts and hepatic and kidney function was performed a minimum of two times weekly. The evaluation of electrolytes was done up to a minimum of 3 weeks after the end of treatment with antifungal monoprophylaxis. Blood analyses were documented the day before the start of oral monoprophylaxis with one of the three azoles (baseline), as well as the maximum or minimum values during and at the end, defined as the last day of treatment with antifungal prophylaxis.

\section{Assessment of efficacy}

All patients were monitored for clinical signs of infection, laboratory analyses, and radiological workup if indicated. The absence of clinically relevant symptoms such as fever or coughing and deviations of laboratory values beyond the normal range indicating a fungal infection were regarded as successful treatment. According to the European Organization for Research and Treatment of Cancer/National Institute of Allergy and Infectious Diseases Mycoses Study Group (EORTC/MSG) criteria of 2002 and 2008, invasive fungal infections were classified as proven, probable, and possible $[30,31]$. The galactomannan antigen was measured until the occurrence of fever with duration of $72 \mathrm{~h} \geq 38.5{ }^{\circ} \mathrm{C}$ by the Platelia ${ }^{\mathrm{TM}}$ Aspergillus enzyme-linked immunosorbent assay according to the manufacturer's protocol (Bio-Rad Laboratories, Munich, Germany). The non-occurrence of clinical or microbiological signs of invasive fungal breakthrough infection during the observation period with antifungal monoprophylaxis was considered as successful antifungal treatment.

Statistical analysis

This retrospective analysis included 93 pediatric patients who received antifungal monoprophylaxis with fluconazole, itraconazole, or posaconazole after chemotherapy or during immunosuppressant therapy. The statistical comparison of differences between the results and normal range values of liver and kidney parameters and electrolytes was performed by one-sample $t$-tests. This took into account the $95 \%$ confidence intervals. The inferential statistical analysis between the baseline values and maximum and minimum parameters, as well as the parameters at the cessation of antifungal monoprophylaxis, was performed using the Friedman twoway analysis of variance (ANOVA) by ranks. Values were only considered significant if they were above the ageadjusted reference. The analysis of hepatic and renal function parameters are presented as mean values + standard deviation (SD). Differences in the frequencies of medication groups, for example at primary diagnosis, application of steroids, or incidence of breakthrough infections when comparing the three patient groups (with $n=31, n=32$, and $n=30$ patients), were tested by the $k$ proportions test. Medications with available contingency tables for up to four classes were first calculated using Fisher's exact test. This was followed by a $k$ proportions test for each individual class (i.e., first a global test for the entire frequency table and then separate tests for each class). For statistical comparison of the three groups regarding clinical and laboratory adverse events during treatment with antifungal prophylaxis, the arithmetic mean values of the three medication groups with a one-way ANOVA were tested for differences. Values of $p<0.05(*), p<0.01(* *)$ and $p<0.001$ $(* * *)$ were defined as significant. XLSTAT 2013 (AddinSoft, Paris, France) or GraphPad Prism ${ }^{\circledR}$ Version 5.04 for Windows (GraphPad Software, La Jolla, CA, USA) were used for the statistical analyses. Graphs were created with GraphPad Prism ${ }^{\circledR}$ Version 5.04 for Windows. 


\section{Results}

\section{Patient characteristics}

This single-center analysis involved the evaluation of 93 pediatric patients with hemato-oncological malignancies aged between 9 months and 17.7 years who received an antifungal monoprophylaxis with fluconazole, itraconazole, or posaconazole during a period of prolonged neutropenia ( $>5$ days). The median age in the fluconazole group was
14 years (range 1-17.5 years), while the itraconazole and posaconazole groups had medians of 12 years (range 117.7 years) and 11 years (range 9 months to 17.4 years), respectively. Significant differences in clinical characteristics were noted regarding the number of children with ALL $(p=0.009)$, ALL relapse $(p=0.018)$, and AML $(p=0.0003)$ included in this analysis, but no significant differences were found in the AML relapse group $(p=0.215)$. The percentage of all these types of diagnoses of the fluconazole group (i.e., $54.8 \%$ acute leukemia; 17 of 31 patients) was comparable

Table 2 Treatment regimens

\begin{tabular}{|c|c|c|c|c|c|}
\hline \multicolumn{2}{|l|}{ Characteristics } & \multirow{2}{*}{$\begin{array}{l}\text { Fluconazole }(n=31) \\
\text { No. of patients }(\%)\end{array}$} & \multirow{2}{*}{$\begin{array}{l}\text { Itraconazole }(n=32) \\
8(25.0)\end{array}$} & \multirow{2}{*}{$\begin{array}{l}\text { Posaconazole }(n=30) \\
8(26.7)\end{array}$} & \multirow{2}{*}{$\begin{array}{c}p \text {-Value } \\
<0.0001\end{array}$} \\
\hline Alkylating antineoplastic agent & $\mathrm{CPM}$ & & & & \\
\hline & Dacarbazine & $2(6.5)$ & $0(0.0)$ & $1(3.3)$ & 0.350 \\
\hline & Ifosfamide & $10(32.3)$ & $9(28.1)$ & $6(20.0)$ & 0.548 \\
\hline & Melphalan & $0(0.0)$ & $0(0.0)$ & $1(3.3)$ & 0.346 \\
\hline \multirow[t]{3}{*}{ Anthracyclines } & Daunorubicin & $12(38.7)$ & $14(43.8)$ & $8(26.7)$ & 0.360 \\
\hline & Doxorubicin & $13(41.9)$ & $3(9.4)$ & $1(3.3)$ & 0.0001 \\
\hline & Idarubicin & $2(6.5)$ & $15(46.9)$ & $1(3.3)$ & $<0.0001$ \\
\hline \multicolumn{6}{|l|}{ Antimetabolites } \\
\hline Folic acid analogues & Methotrexate & $23(74.2)$ & $10(31.3)$ & $6(20.0)$ & $<0.0001$ \\
\hline \multirow[t]{5}{*}{ Purine analogues } & Clofarabine & $0(0.0)$ & $1(3.1)$ & $3(10.0)$ & 0.145 \\
\hline & Fludarabine & $1(3.2)$ & $4(12.5)$ & $2(6.7)$ & 0.369 \\
\hline & Nelarabine & $0(0.0)$ & $0(0.0)$ & $1(3.3)$ & 0.346 \\
\hline & Tioguanine & $3(9.7)$ & $7(21.9)$ & $3(10.0)$ & 0.282 \\
\hline & 6-Mercaptopurine & $9(29.0)$ & $5(15.6)$ & $5(16.7)$ & 0.345 \\
\hline \multirow[t]{2}{*}{ Pyrimidine analogues } & Cytarabine & $22(71.0)$ & $26(81.3)$ & $15(50.0)$ & 0.028 \\
\hline & 2-CDA & $1(3.2)$ & $3(9.4)$ & $0(0.0)$ & 0.179 \\
\hline Enzymes & Asparaginase & $12(38.7)$ & $10(31.3)$ & $9(30.0)$ & 0.735 \\
\hline \multirow[t]{2}{*}{ Platinum complex compounds } & Carboplatin & $1(3.2)$ & $0(0.0)$ & $0(0.0)$ & 0.364 \\
\hline & Cisplatin & $4(12.9)$ & $1(3.1)$ & $0(0.0)$ & 0.065 \\
\hline \multirow[t]{3}{*}{ Topoisomerase inhibitors } & Etoposide & $13(41.9)$ & $17(53.1)$ & $6(20.0)$ & 0.025 \\
\hline & Mitoxantrone & $2(6.5)$ & $10(31.3)$ & $0(0.0)$ & 0.001 \\
\hline & Topotecan & $1(3.2)$ & $0(0.0)$ & $0(0.0)$ & 0.364 \\
\hline \multirow[t]{3}{*}{ Vinca alkaloids } & Vinblastine & $0(0.0)$ & $0(0.0)$ & $1(3.3)$ & 0.346 \\
\hline & Vincristine & $19(61.3)$ & $11(34.4)$ & $10(33.3)$ & 0.042 \\
\hline & Vindesine & $8(25.8)$ & $6(18.8)$ & $5(16.7)$ & 0.648 \\
\hline \multirow[t]{3}{*}{ Intrathecal medication } & Cytarabine & $14(45.2)$ & $24(75.0)$ & $13(43.3)$ & 0.018 \\
\hline & methotrexate & $22(71.0)$ & $26(81.3)$ & $12(40.0)$ & 0.002 \\
\hline & Predniso(n)/lon & $14(45.2)$ & $24(75.0)$ & $11(36.7)$ & 0.006 \\
\hline \multirow[t]{4}{*}{ Antibodies } & ATG & $0(0.0)$ & $0(0.0)$ & $1(3.3)$ & 0.346 \\
\hline & Blinatumomab & $0(0.0)$ & $0(0.0)$ & $1(3.3)$ & 0.346 \\
\hline & CD19 antibody & $0(0.0)$ & $1(3.1)$ & $0(0.0)$ & 0.382 \\
\hline & Rituximab & $0(0.0)$ & $0(0.0)$ & $2(6.7)$ & 0.117 \\
\hline \multirow[t]{2}{*}{ Tyrosine kinase inhibitors } & Nilotinib & $0(0.0)$ & $0(0.0)$ & $1(3.3)$ & 0.346 \\
\hline & Imatinib & $0(0.0)$ & $1(3.1)$ & $0(0.0)$ & 0.382 \\
\hline
\end{tabular}

$A T G$ anti-thymocyte globulin; $C P M$ cyclophosphamide; $C S A$ ciclosporin A; 2-CDA 2-chloro-2'-deoxyadenosine Statistical tests: $k$ proportions test with XLSTAT 2013 
( $p=0.1611)$ to the posaconazole group $(56.7 \% ; 17$ of 30 patients), but significantly different $(p=0.0054)$ from the itraconazole group $(87.5 \%$; 28 of 32 patients; see Table 1). Information on chemotherapy regimens is presented in Table 2.

Treatment and observation period

The median observation periods were 135 days (range 47-212 days) for the fluconazole group, 104 days (range 47-186) for the itraconazole group, and 107 days (range 28-236 days) for the posaconazole group. The median treatment period was 116 days (range 25-189 days) for the fluconazole group, 85 days (range 23-164 days) for the itraconazole group, and 86 days (range 6-214 days) for the posaconazole group.
Mortality

Seven $(7.5 \%)$ of the 93 pediatric patients died during the observation period. None of the patients included in the analysis died of invasive fungal infection. Four patients died due to a relapse of their primary diagnosis. Two patients died of multiple organ failure due to sepsis, while another one died of cardiac failure after chemotherapy.

\section{Neutropenia}

The count of prolonged neutropenic periods (neutrophil counts $<500 / \mu \mathrm{L} ;>5$ days) were similar in all three groups, with medians of two periods (range 1-7) in the fluconazole group, two periods (range 1-6) in the itraconazole group, and
Table 3 Clinical and laboratory adverse events during antifungal prophylaxis
Statistical tests: $k$ proportions test with XLSTAT 2013

\begin{tabular}{|c|c|c|c|c|}
\hline Characteristics & $\begin{array}{l}\text { Fluconazole } \\
(n=31) \\
\text { No. of patients }(\%)\end{array}$ & $\begin{array}{l}\text { Itraconazole } \\
(n=32)\end{array}$ & $\begin{array}{l}\text { Posaconazole } \\
(n=30)\end{array}$ & $p$-Value \\
\hline \multicolumn{5}{|l|}{ Drug-related adverse events } \\
\hline Clinical (total) & $4(12.9)$ & $5(15.6)$ & $3(10.0)$ & 0.804 \\
\hline Fever & $0(0.0)$ & $1(3.1)$ & $0(0.0)$ & 0.382 \\
\hline Headache & $1(3.2)$ & $0(0.0)$ & $0(0.0)$ & 0.364 \\
\hline Nausea & $1(3.2)$ & $1(3.1)$ & $1(3.3)$ & 0.999 \\
\hline Diarrhea & $2(6.5)$ & $1(3.1)$ & $0(0.0)$ & 0.362 \\
\hline Exanthema & $0(0.0)$ & $1(3.1)$ & $0(0.0)$ & 0.382 \\
\hline Abdominal pain & $0(0.0)$ & $1(3.1)$ & $2(6.7)$ & 0.338 \\
\hline \multicolumn{5}{|l|}{ Increase in alanine aminotransferase } \\
\hline$>1.5 \times$ normal value $39 \mathrm{U} / \mathrm{L}$ & $8(25.8)$ & $7(21.8)$ & $3(10.0)$ & 0.267 \\
\hline$>2.5 \times$ normal value $39 \mathrm{U} / \mathrm{L}$ & $4(12.9)$ & $4(12.5)$ & $5(16.7)$ & 0.874 \\
\hline \multicolumn{5}{|c|}{ Increase in aspartate aminotransferase } \\
\hline$>1.5 \times$ normal value $39 \mathrm{U} / \mathrm{L}$ & $4(12.9)$ & $2(6.6)$ & $5(16.7)$ & 0.435 \\
\hline$>2.5 \times$ normal value $39 \mathrm{U} / \mathrm{L}$ & $3(9.7)$ & $3(9.4)$ & $1(3.3)$ & 0.571 \\
\hline \multicolumn{5}{|l|}{ Increase in alkaline phosphatase } \\
\hline$>1.5 \times$ normal value $320 \mathrm{U} / \mathrm{L}$ & $1(3.2)$ & $0(0.0)$ & $0(0.0)$ & 0.364 \\
\hline$>2.5 \times$ normal value $320 \mathrm{U} / \mathrm{L}$ & $0(0.0)$ & $0(0.0)$ & $0(0.0)$ & 1.0 \\
\hline \multicolumn{5}{|l|}{ Increase in total bilirubin } \\
\hline$>1.5 \times$ normal value $1.1 \mathrm{mg} / \mathrm{dl}$ & $1(3.2)$ & $2(6.3)$ & $2(6.7)$ & 0.807 \\
\hline$>2.5 \times$ normal value $1.1 \mathrm{mg} / \mathrm{dl}$ & $0(0.0)$ & $0(0.0)$ & $0(0.0)$ & 1.0 \\
\hline \multicolumn{5}{|l|}{ Increase in direct bilirubin } \\
\hline$>1.5 \times$ normal value $0.3 \mathrm{mg} / \mathrm{dl}$ & $2(6.5)$ & $3(9.4)$ & $2(6.7)$ & 0.887 \\
\hline$>2.5 \times$ normal value $0.3 \mathrm{mg} / \mathrm{dl}$ & $0(0.0)$ & $3(9.4)$ & $1(3.3)$ & 0.177 \\
\hline \multicolumn{5}{|l|}{ Increase in creatinine } \\
\hline$>1.5 \times$ normal value $0.7 \mathrm{mg} / \mathrm{dl}$ & $1(3.2)$ & $0(0.0)$ & $1(3.3)$ & 0.585 \\
\hline$>2.5 \times$ normal value $0.7 \mathrm{mg} / \mathrm{dl}$ & $0(0.0)$ & $0(0.0)$ & $0(0.0)$ & 1.0 \\
\hline \multicolumn{5}{|l|}{ Increase in urea } \\
\hline$>1.5 \times$ normal value $46 \mathrm{mg} / \mathrm{dl}$ & $1(3.2)$ & $0(0.0)$ & $0(0.0)$ & 0.364 \\
\hline$>2.5 \times$ normal value $46 \mathrm{mg} / \mathrm{dl}$ & $0(0.0)$ & $0(0.0)$ & $0(0.0)$ & 1.0 \\
\hline \multicolumn{5}{|l|}{ Decrease in potassium } \\
\hline$<3.4 \mathrm{mmol} / \mathrm{L}$ & $2(6.5)$ & $3(9.4)$ & $2(6.7)$ & 0.867 \\
\hline$<2.4 \mathrm{mmol} / \mathrm{L}$ & $0(0.0)$ & $0(0.0)$ & $0(0.0)$ & 1.0 \\
\hline
\end{tabular}


two periods (range 1-6) in the posaconazole group. The median durations of the prolonged neutropenic periods were 7 days (range 5-47 days), 9 days (range 6-78 days), and 7 days (range 5-214 days), with means of $8.9 \pm 3.2,12.6 \pm 6.1$, and $17.4 \pm 11.4$, respectively.

\section{Adverse events}

The spectrum of drug-related adverse events caused by one of the three azoles was characterized primarily by gastrointestinal symptoms such as abdominal pain, nausea, or diarrhea in all three groups. Other adverse events in the fluconazole group were headache, while patients in the itraconazole group experienced fever and exanthema (Table 3). Adverse events that may be related to antifungal treatment were observed in four patients in the fluconazole group, in five patients in the itraconazole group, and in three patients in the posaconazole group. The differences between these three groups were not significant $(p=0.804)$. Due to adverse events, oral antifungal prophylaxis was withdrawn for two of the four patients treated with fluconazole, for three of the five patients treated with itraconazole, and for one of the three patients treated with posaconazole.

\section{Efficacy analysis}

All 93 pediatric patients were included in the efficacy analysis (Table 4). Overall, there were two invasive fungal breakthrough infections in the fluconazole group, three in the itraconazole group, and one in the posaconazole group, according to the EORTC guidelines [30, 31]. In each of the three azole groups, there was one proven fungal infection. Probable infections did not occur. Possible fungal infections were seen

Table 4 Breakthrough invasive fungal infections during antifungal prophylaxis

\begin{tabular}{lllll}
\hline Characteristics & $\begin{array}{l}\text { Fluconazole } \\
(n=31) \\
\text { No. of patients }\end{array}$ & $\begin{array}{l}\text { Itraconazole } \\
(n=32)\end{array}$ & $\begin{array}{l}\text { Posaconazole } \\
(n=30)\end{array}$ & $p$-Value \\
& 2 & 3 & 1 & 0.626 \\
$\begin{array}{l}\text { Invasive fungal } \\
\text { infection: total no. }\end{array}$ & & & & \\
$\begin{array}{c}\text { Aspergillus spp. } \\
\text { Proven }\end{array}$ & 1 & 1 & 1 & 0.999 \\
$\begin{array}{l}\text { Probable } \\
\text { Possible }\end{array}$ & - & - & - & \\
$\begin{array}{c}\text { Candida } \text { spp. } \\
\text { Proven }\end{array}$ & 1 & 2 & - & 0.380 \\
$\begin{array}{l}\text { Probable } \\
\text { Possible }\end{array}$ & - & - & - & \\
Others & - & - & - & \\
\hline
\end{tabular}

Statistical tests: $k$ proportions test with XLSTAT 2013 in one patient in the fluconazole group and two patients in the itraconazole group.

In the fluconazole group, one patient with high-risk ALL, who presented with neutropenia and coughs, experienced an Aspergillus spp. infection with typical fungus infiltrates in the lungs and brain. The galactomannan antigen was positive in more than two consecutive blood analyses. There was also positive microbiological detection in the sputum. An antifungal combination therapy with caspofungin, voriconazole, and liposomal amphotericin B was given. Both the pulmonary nodule and two cerebral foci were resected. After clinical discharge, antifungal therapy was given with posaconazole for a further six months. During this time, there were no more signs of invasive fungal infection. A possible invasive infection was observed in this group for one patient suffering from ALL. The computed tomography (CT) scan showed foci that were suspected to be fungi herds. However, galactomannan antigen was negative.

In the itraconazole group, one patient with AML experienced thoracic pain and fever during the neutropenia period between chemotherapy cycles. The CT scan showed an Aspergillus pneumonia with a halo sign and increase in galactomannan antigen. The patient was treated with a triple antifungal prophylaxis including caspofungin, voriconazole, and liposomal amphotericin B. After resection of the pulmonary foci, antifungal therapy was continued with antifungal monotherapy with liposomal amphotericin B. The patient received oral antifungal therapy with posaconazole after clinical discharge for a further five months. During this time, there was no sign of invasive fungal infection. In this group, two possible fungal infections occurred in patients with AML who underwent chemotherapy cycles. Typical fungus lung infiltrates were found on the CT scan. In both patients, the galactomannan antigen was not detectable. A lung lavage was not performed.

In the posaconazole group, one patient with granulocytopenia experienced fever and pain in the right lower abdomen. Up to that point, the pediatric patient had been treated with posaconazole antifungal monoprophylaxis for a period of 104 days. An appendectomy was performed and its biopsy material showed evidence of an Aspergillus infection. The galactomannan antigen and blood cultures were negative during the entire period when antifungal prophylaxis with posaconazole was given. The antifungal prophylaxis was continued with posaconazole in therapeutic dosage for another 110 days after the appendectomy until the planned stem cell transplantation. At the time of HSCT, intravenous antifungal prophylaxis was given with liposomal amphotericin B during the conditioning regimen and on day 1 after HSCT with caspofungin. Shortly before clinical discharge, there was a change to antifungal oral monoprophylaxis with posaconazole until reaching immune reconstitution $(\mathrm{CD} 3+$ cells $200 / \mu \mathrm{L}$ and CD4+ cells to $100 / \mu \mathrm{L}$; until day 120 after transplantation). 
There were no more signs of an invasive fungal infection during the entire period after stem cell transplantation. A possible invasive fungal infection did not occur in this patient group.

A probable invasive infection did not occur in any of the three azole groups.

\section{Safety and tolerance}

The blood analysis of liver and kidney parameters showed a significant increase beyond the upper normal limit of ALT between baseline and maximum in all three groups, i.e., fluconazole $(p=0.031)$, itraconazole $(p=0.015)$, and posaconazole $(p=0.007)$, and a significant increase of AST between baseline and maximum in the fluconazole $(p=0.049)$ and posaconazole groups $(p=0.005)$ (Fig. 1).

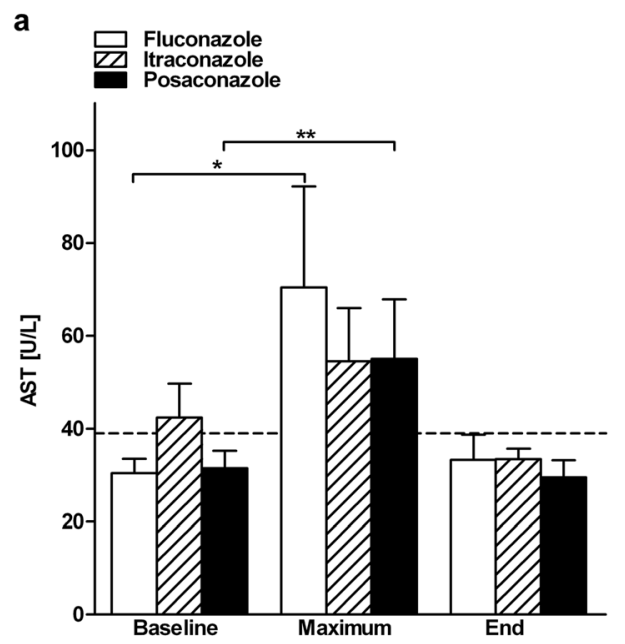

c

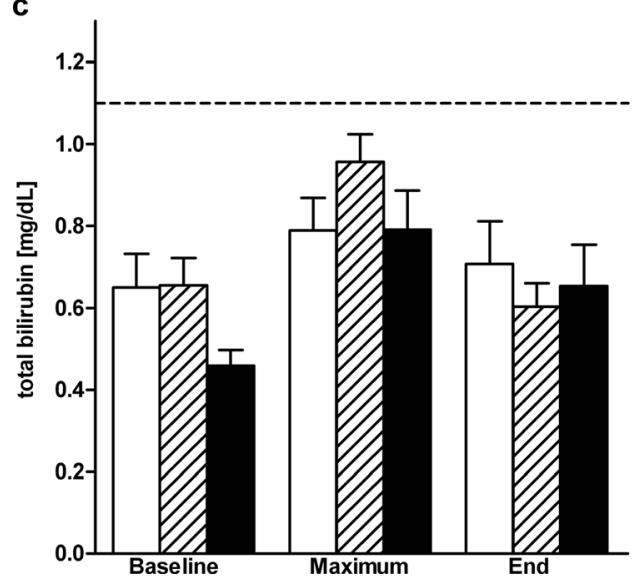

Fig. 1 Hepatotoxicity. The data show mean values + standard deviation (SD) of transaminases and total bilirubin on the day before the start of oral antifungal prophylaxis (Baseline) and maximum values during (Maximum) and at the end (End) of treatment with fluconazole, itraconazole, and posaconazole. Normal values are indicated by the dotted lines. a Mean $+\mathrm{SD}$ of serum concentration of aspartate aminotransferase $(A S T)$ (normal<39 U/L). ); $p$-values maximum compared to baseline: fluconazole $(p=0.049)$, itraconazole $(p>0.05)$, and posaconazole $(p=0.005)$. b Mean + SD of serum concentration of alanine
An increase in ALT of $>1.5$ and 2.5 times the normal value occurred in a total of 12 pediatric patients in the fluconazole group, 11 pediatric patients in the itraconazole group, and eight pediatric patients in the posaconazole group. AST $>1.5$ and 2.5 times the normal value occurred in a total of seven pediatric patients in the fluconazole group, five pediatric patients in the itraconazole group, and six pediatric patients in the posaconazole group (Table 3). The total and direct bilirubin and AP showed no significant increase above the normal values during antifungal prophylaxis with any of the three azoles. Kidney parameters creatinine and urea were not significantly elevated beyond the upper limit of the normal range during antifungal monoprophylaxis in any of the treatment groups (Fig. 2). In all three groups, there was no significant decrease in potassium during antifungal prophylaxis with any of the three azoles.

b

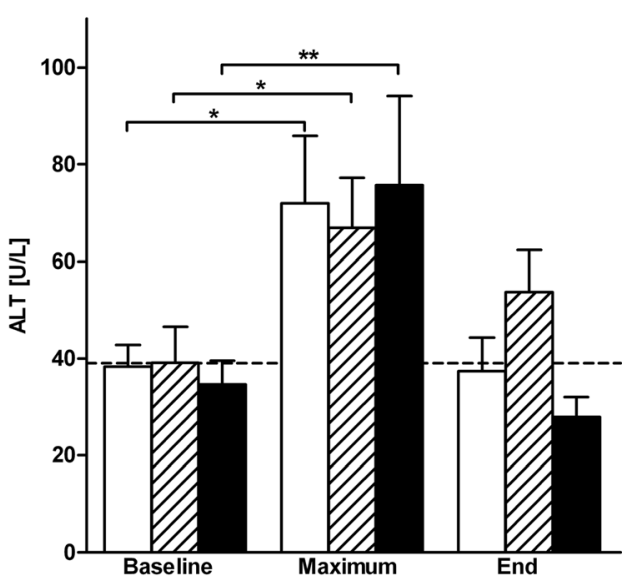

aminotransferase $(A L T)$ (normal $<39 \mathrm{U} / \mathrm{L})$; $p$-values maximum compared to baseline: fluconazole $(p=0.031)$, itraconazole $(p=0.015)$, and posaconazole $(p=0.007)$. c Mean + SD of serum concentration of total bilirubin (normal $<1.1 \mathrm{mg} / \mathrm{dL}$ ); $p$-values maximum compared to baseline: fluconazole $(p>0.05)$, itraconazole $(p>0.05)$, and posaconazole $(p>0.05)$. None of the changes in the ALT, AST, or total bilirubin serum concentrations were clinically relevant. Statistical significance was tested by the Wilcoxon matched-pairs signed-rank test. ${ }^{*} p<0.05 ; * * p<0.01$ 
a

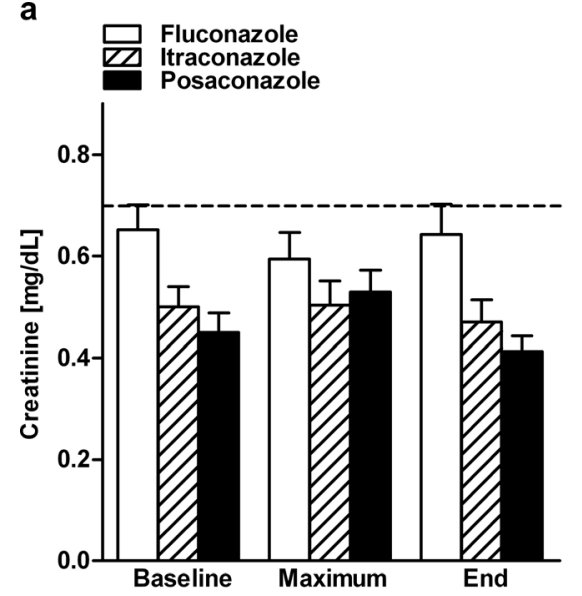

b

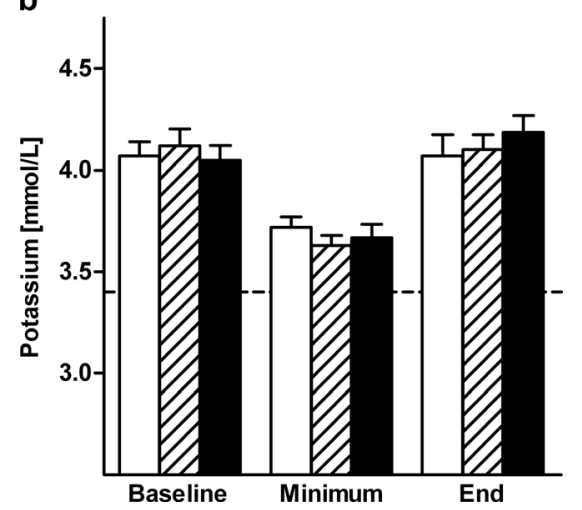

Fig. 2 Nephrotoxicity. The data show mean values + standard deviation (SD) of renal parameters on the day before the start of oral antifungal prophylaxis (Baseline) and maximum (Maximum) or minimum (Minimum) values during and at the end of fluconazole, itraconazole, and posaconazole treatment. Normal values are indicated by the dotted lines. a Mean + SD of serum concentration of creatinine (normal $<0.7 \mathrm{mg} / \mathrm{dL}$ ). $\mathbf{b}$ Mean $+\mathrm{SD}$ of serum concentration of potassium (normal $>3.4 \mathrm{mmol} / \mathrm{L}$ ). Statistical significance was tested by the Wilcoxon matched-pairs signed-rank test

\section{Discussion}

The goal of antifungal prophylaxis treatment in pediatric patients with prolonged neutropenia is to prevent invasive fungal infections, thereby minimizing mortality. While several evidence-based guidelines are available for adults with hemato-oncological malignancies [32-36], there are only limited data on pediatric patients $[37,38]$. Due to the favorable results of oral antifungal prophylaxis with posaconazole in adults with myelodysplastic syndromes (MDS) and AML in randomized clinical trials involving more than 300 high-risk patients with neutropenia and more than 300 transplanted patients with GvHD [11, 12], we have also been using oral antifungal prophylaxis with posaconazole at our clinic since 2007. The excellent results in the first 60 pediatric patients treated with posaconazole after HSCT and comparably successful analysis of posaconazole with itraconazole and voriconazole in 150 pediatric patients after allogeneic HSCT $[27,28]$ were the decisive factors to perform this retrospective analysis. This analysis, which includes 93 pediatric patients with a median age of 12 years, shows that the incidence of invasive fungal infections in pediatric patients was low under each of the three azoles posaconazole, itraconazole, and fluconazole.

In each of the three treatment groups, there was one proven fungal infection, but no occurrence of probable fungal infections. Possible fungal infections were observed in both the itraconazole and fluconazole groups, but not in the posaconazole group. The occurrence of proven fungal infection in all three groups raises the question as to whether the dosage and resorption of the extendedspectra azoles were adequate, as regular assessment of trough levels had not been performed.

The data on pediatric patients regarding the efficacy, safety, and tolerability of posaconazole are mainly confined to analyses of small numbers of patients. A multicenter retrospective analysis, which examined the treatment of proven or probable invasive fungal infections, showed a remission in 9 of the 15 pediatric patients under salvage therapy with posaconazole [39]. Another retrospective study in 15 children with proven $(n=1)$, probable $(n=10)$, or possible $(n=1)$ fungal infection after HSCT or neutropenia after chemotherapy showed that posaconazole, as secondary prophylaxis, is to be regarded as being safe and well tolerated by children [40]. After 90 days of treatment with posaconazole, significantly improved radiological results were shown in nine pediatric patients. Twelve months after the onset of fungal infection in 12 patients, the survival rate was $91.67 \%$.

In a single-center retrospective study, 2 of 53 pediatric patients given intravenous and then oral antifungal prophylaxis with itraconazole after HSCT experienced a proven fungal infection [21]. A comparison of the efficacy of itraconazole, voriconazole, fluconazole, and posaconazole as antifungal prophylaxis in adults showed that invasive fungal infections occurred the least often (in $3 \%$ of cases) in patients given posaconazole, while patients treated with fluconazole experienced invasive fungal infections at the highest rate (25\% of cases) [41]. More effective prevention of invasive fungal infections and, thus, an improvement in the survival rate was observed with posaconazole antifungal prophylaxis in $2 \%$ of 304 adult patients treated, compared to itraconazole and fluconazole, where fungal infection occurred in $8 \%$ of the cases [11].

The results of the present survey show that clinical, potentially azole-related adverse events are higher in the fluconazole $(n=4)$ and itraconazole $(n=5)$ groups than in the posaconazole group $(n=3)$. However, these results are not statistically significant.

Mainly gastrointestinal adverse events such as nausea, diarrhea, and abdominal pain occurred in all three groups with 
the same frequency. Fortunately, no azole-associated peripheral neuropathy side effect was observed in any of the patients from the three groups. Similar results have been reported in several studies on long-term triazole therapy $[42,43]$. These results can probably be attributed to the cessation of antifungal prophylaxis with one of the azoles $24 \mathrm{~h}$ before the start of chemotherapy and $24 \mathrm{~h}$ after chemotherapy with the vinca alkaloid.

In a multicenter randomized trial with adults, the comparison of itraconazole with fluconazole showed that itraconazole is more effective as a long-term prophylaxis. However, while taking itraconazole (both intravenous and oral), gastrointestinal side effects occurred significantly $(p=0.02)$ more often than with fluconazole recipients [16].

In a randomized, double-blind trial of 600 patients after stem cell transplantation with GvHD, antifungal prophylaxis of invasive fungal infections with oral posaconazole in 301 patients was compared to oral fluconazole in 299 patients. Gastrointestinal disorders such as diarrhea, nausea, and abdominal pain occurred more often in the fluconazole group $(18 \%)$ than in the posaconazole group (14\%) [44]. In an analysis using data derived from 12 clinical studies of fluconazole as prophylaxis or treatment for a variety of fungal infections including 562 predominantly immunocompromised pediatric patients, the most common side effects were associated with the gastrointestinal tract (7.7\%) [44]. In studies which analyzed the safety and tolerability of posaconazole in pediatric patients, side effects such as nausea and vomiting occurred at varying frequencies $[27,39,40]$.

In the present analysis, the transaminases ALT and AST increased significantly beyond the normal ranges during antifungal prophylaxis, whereas total bilirubin, direct bilirubin, creatinine, urea, and potassium showed no significant changes during the treatment. Changes in the transaminases of the itraconazole and posaconazole groups in the present investigation correspond to prior observations made at our hospital during antifungal prophylaxis with these azoles [27, 28]. In a retrospective single-center study, $10(18.9 \%)$ out of the 53 pediatric patients that received antifungal prophylaxis with itraconazole after HSCT were found to have at least a doubling of the baseline value of AST [21]. In different published studies with immunocompromised pediatric and juvenile patients suffering from hemato-oncological malignancies, transaminases ALT and AST were also increased under antifungal prophylaxis and therapy with fluconazole in $6-18 \%$ of the recipients [44].

In summary, in the present survey, the incidence of invasive fungal infections in pediatric patients was similarly low under each of the azoles during the observation period. One case of proven aspergillosis occurred in each group. While this can be explained in the case of fluconazole, it remains an open question as to why extended-spectra azoles were not capable of preventing these breakthrough infections. Inadequate dosing and/or inadequate trough levels due to malabsorption may have contributed to the treatment failures. A few cases of possible invasive fungal infection under fluconazole and itraconazole, but none under posaconazole, were observed. Potentially clinical drug-related adverse events were similar in the three treatment groups. Laboratory parameters were comparable during fluconazole, itraconazole, and posaconazole treatment. Larger cohorts and a prospective setting are needed in order to establish the efficacy of prophylactic use of extended-spectra azoles in this patient cohort.

Acknowledgments This work was funded in part by MSD Sharp \& Dohme GmbH, Germany. The authors declare that they have no conflict of interest. Redundant publication: no substantial overlaps with previous publications.

Ethical standards This retrospective analysis occurred in accordance with the Declaration of Helsinki and was performed under the waiver for retrospective anonymized studies in accordance with the institutional ethics regulations. Data were collected retrospectively, entered in a standardized case report form, and anonymized. Informed consent was obtained from the patients or their legal representatives.

Open Access This article is distributed under the terms of the Creative Commons Attribution License which permits any use, distribution, and reproduction in any medium, provided the original author(s) and the source are credited.

\section{References}

1. Cornely OA, Böhme A, Reichert D, Reuter S, Maschmeyer G, Maertens J, Buchheidt D, Paluszewska M, Arenz D, Bethe U, Effelsberg J, Lövenich H, Sieniawski M, Haas A, Einsele H, Eimermacher H, Martino R, Silling G, Hahn M, Wacker S, Ullmann AJ, Karthaus M; Multinational Case Registry of the Infectious Diseases Working Party of the German Society for Hematology and Oncology (2008) Risk factors for breakthrough invasive fungal infection during secondary prophylaxis. J Antimicrob Chemother 61(4): 939-946

2. de Pauw BE, Meunier F (1999) The challenge of invasive fungal infection. Chemotherapy 45(Suppl 1):1-14

3. Steinbach WJ (2010) Invasive aspergillosis in pediatric patients. Curr Med Res Opin 26(7):1779-1787

4. Zaoutis T (2010) Candidemia in children. Curr Med Res Opin 26(7): 1761-1768

5. Lin SJ, Schranz J, Teutsch SM (2001) Aspergillosis case-fatality rate: systematic review of the literature. Clin Infect Dis 32(3):358-366

6. Dornbusch HJ, Manzoni P, Roilides E, Walsh TJ, Groll AH (2009) Invasive fungal infections in children. Pediatr Infect Dis J 28(8): 734-737

7. Ninane J (1994) A multicentre study of fluconazole versus oral polyenes in the prevention of fungal infection in children with hematological or oncological malignancies. Multicentre Study Group. Eur J Clin Microbiol Infect Dis 13(4):330-337

8. Simon A, Besuden M, Vezmar S, Hasan C, Lampe D, Kreutzberg S, Glasmacher A, Bode U, Fleischhack G (2007) Itraconazole prophylaxis in pediatric cancer patients receiving conventional chemotherapy or autologous stem cell transplants. Support Care Cancer 15(2): 213-220 
9. Yunus S, Pieper S, Kolve H, Goletz G, Jürgens H, Groll AH (2014) Azole-based chemoprophylaxis of invasive fungal infections in paediatric patients with acute leukaemia: an internal audit. J Antimicrob Chemother 69(3):815-820

10. Cáp J, Mojzesova A, Kayserova E, Bubánska E, Hatiar K, Trupl J, Krcméry V Jr (1993) Fluconazole in children: first experience with prophylaxis in chemotherapy-induced neutropenia in pediatric patients with cancer. Chemotherapy 39(6):438-442

11. Cornely OA, Maertens J, Winston DJ, Perfect J, Ullmann AJ, Walsh TJ, Helfgott D, Holowiecki J, Stockelberg D, Goh YT, Petrini M, Hardalo C, Suresh R, Angulo-Gonzalez D (2007) Posaconazole vs. fluconazole or itraconazole prophylaxis in patients with neutropenia. N Engl J Med 356(4):348-359

12. Ullmann AJ, Lipton JH, Vesole DH, Chandrasekar P, Langston A, Tarantolo SR, Greinix H, Morais de Azevedo W, Reddy V, Boparai N, Pedicone L, Patino H, Durrant S (2007) Posaconazole or fluconazole for prophylaxis in severe graft-versus-host disease. N Engl $\mathrm{J}$ Med 356(4):335-347

13. Kung HC, Johnson MD, Drew RH, Saha-Chaudhuri P, Perfect JR (2014) Clinical effectiveness of posaconazole versus fluconazole as antifungal prophylaxis in hematology-oncology patients: a retrospective cohort study. Cancer Med 3(3):667-673

14. Grant SM, Clissold SP (1990) Fluconazole. A review of its pharmacodynamic and pharmacokinetic properties, and therapeutic potential in superficial and systemic mycoses. Drugs 39(6):877-916

15. Pfizer GmbH (2011) Diflucan ${ }^{\circledR}$ : fluconazole. Fachinformation

16. Winston DJ, Maziarz RT, Chandrasekar PH, Lazarus HM, Goldman M, Blumer JL, Leitz GJ, Territo MC (2003) Intravenous and oral itraconazole versus intravenous and oral fluconazole for long-term antifungal prophylaxis in allogeneic hematopoietic stem-cell transplant recipients. A multicenter, randomized trial. Ann Intern Med 138(9):705-713

17. Anaissie EJ, Kontoyiannis DP, Huls C, Vartivarian SE, Karl C, Prince RA, Bosso J, Bodey GP (1995) Safety, plasma concentrations, and efficacy of high-dose fluconazole in invasive mold infections. J Infect Dis 172(2):599-602

18. Cuenca-Estrella M, Rodríguez-Tudela JL, Mellado E, MartínezSuárez JV, Monzón A (1998) Comparison of the in-vitro activity of voriconazole (UK-109,496), itraconazole and amphotericin B against clinical isolates of Aspergillus fumigatus. J Antimicrob Chemother 42(4):531-533

19. Espinel-Ingroff A, Canton E, Gibbs D, Wang A (2007) Correlation of Neo-Sensitabs tablet diffusion assay results on three different agar media with CLSI broth microdilution M27-A2 and disk diffusion M44-A results for testing susceptibilities of Candida spp. and Cryptococcus neoformans to amphotericin B, caspofungin, fluconazole, itraconazole, and voriconazole. J Clin Microbiol 45(3):858-864

20. Janssen-Cilag GmbH (2011) Sempera ${ }^{\circledR} 7$ Kapseln: itraconazole. Fachinformation

21. Grigull L, Kuehlke O, Beilken A, Sander A, Linderkamp C, Schmid H, Seidemann K, Sykora KW, Schuster FR, Welte K (2007) Intravenous and oral sequential itraconazole antifungal prophylaxis in paediatric stem cell transplantation recipients: a pilot study for evaluation of safety and efficacy. Pediatr Transplant 11(3):261-266

22. Potter M, Donnelly JP (2004) The role of itraconazole in preventing and treating systemic fungal infections in immunocompromised patients. Acta Haematol 111(3):175-180

23. Glasmacher A, Prentice A, Gorschlüter M, Engelhart S, Hahn C, Djulbegovic B, Schmidt-Wolf IG (2003) Itraconazole prevents invasive fungal infections in neutropenic patients treated for hematologic malignancies: evidence from a meta-analysis of 3,597 patients. J Clin Oncol 21(24):4615-4626

24. Morgenstern GR, Prentice AG, Prentice HG, Ropner JE, Schey SA, Warnock DW (1999) A randomized controlled trial of itraconazole versus fluconazole for the prevention of fungal infections in patients with haematological malignancies. U.K.
Multicentre Antifungal Prophylaxis Study Group. Br J Haematol 105(4):901-911

25. Vardakas KZ, Michalopoulos A, Falagas ME (2005) Fluconazole versus itraconazole for antifungal prophylaxis in neutropenic patients with haematological malignancies: a meta-analysis of randomisedcontrolled trials. Br J Haematol 131(1):22-28

26. MSD Sharp \& Dohme GmbH (2013) Noxafil ${ }^{\circledR} 40 \mathrm{mg} / \mathrm{mL}$ suspension: posaconazole. Fachinformation

27. Döring M, Müller C, Johann PD, Erbacher A, Kimmig A, Schwarze CP, Lang P, Handgretinger R, Müller I (2012) Analysis of posaconazole as oral antifungal prophylaxis in pediatric patients under 12 years of age following allogeneic stem cell transplantation. BMC Infect Dis 12:263

28. Döring M, Blume O, Haufe S, Hartmann U, Kimmig A, Schwarze CP, Lang P, Handgretinger R, Müller I (2014) Comparison of itraconazole, voriconazole, and posaconazole as oral antifungal prophylaxis in pediatric patients following allogeneic hematopoietic stem cell transplantation. Eur J Clin Microbiol Infect Dis 33(4): 629-638

29. National Cancer Institute (NCI) (2006) Common terminology criteria for adverse events v3.0 (CTCAE). Cancer Therapy Evaluation Program. NCI, Bethesda. Available online at: http://ctep.cancer.gov/ protocolDevelopment/electronic applications/ctc.htm\#ctc 40. Cited 30 June 2014

30. Ascioglu S, Rex JH, de Pauw B, Bennett JE, Bille J, Crokaert F, Denning DW, Donnelly JP, Edwards JE, Erjavec Z, Fiere D, Lortholary O, Maertens J, Meis JF, Patterson TF, Ritter J, Selleslag D, Shah PM, Stevens DA, Walsh TJ; Invasive Fungal Infections Cooperative Group of the European Organization for Research and Treatment of Cancer; Mycoses Study Group of the National Institute of Allergy and Infectious Diseases (2002) Defining opportunistic invasive fungal infections in immunocompromised patients with cancer and hematopoietic stem cell transplants: an international consensus. Clin Infect Dis 34(1):7-14

31. De Pauw B, Walsh TJ, Donnelly JP, Stevens DA, Edwards JE, Calandra T, Pappas PG, Maertens J, Lortholary O, Kauffman CA, Denning DW, Patterson TF, Maschmeyer G, Bille J, Dismukes WE, Herbrecht R, Hope WW, Kibbler CC, Kullberg BJ, Marr KA, Muñoz P, Odds FC, Perfect JR, Restrepo A, Ruhnke M, Segal BH, Sobel JD, Sorrell TC, Viscoli C, Wingard JR, Zaoutis T, Bennett JE; European Organization for Research and Treatment of Cancer/Invasive Fungal Infections Cooperative Group; National Institute of Allergy and Infectious Diseases Mycoses Study Group (EORTC/ MSG) Consensus Group (2008) Revised definitions of invasive fungal disease from the European Organization for Research and Treatment of Cancer/Invasive Fungal Infections Cooperative Group and the National Institute of Allergy and Infectious Diseases Mycoses Study Group (EORTC/MSG) Consensus Group. Clin Infect Dis 46(12):1813-1821

32. Tomblyn M, Chiller T, Einsele H, Gress R, Sepkowitz K, Storek J, Wingard JR, Young JA, Boeckh MJ; Center for International Blood and Marrow Research; National Marrow Donor program; European Blood and Marrow Transplant Group; American Society of Blood and Marrow Transplantation; Canadian Blood and Marrow Transplant Group; Infectious Diseases Society of America; Society for Healthcare Epidemiology of America; Association of Medical Microbiology and Infectious Disease Canada; Centers for Disease Control and Prevention (2009) Guidelines for preventing infectious complications among hematopoietic cell transplantation recipients: a global perspective. Biol Blood Marrow Transplant 15(10): $1143-1238$

33. Slavin MA, Heath $\mathrm{CH}$, Thursky KA, Morrissey CO, Szer J, Ling LM, Milliken ST, Grigg AP (2008) Antifungal prophylaxis in adult stem cell transplantation and haematological malignancy. Intern Med J 38(6b):468-476 
34. Cornely OA, Böhme A, Buchheidt D, Einsele H, Heinz WJ, Karthaus M, Krause SW, Krüger W, Maschmeyer G, Penack O, Ritter J, Ruhnke M, Sandherr M, Sieniawski M, Vehreschild JJ, Wolf HH, Ullmann AJ (2009) Primary prophylaxis of invasive fungal infections in patients with hematologic malignancies. Recommendations of the Infectious Diseases Working Party of the German Society for Haematology and Oncology. Haematologica 94(1):113-122

35. Dykewicz CA; Centers for Disease Control and Prevention (U.S.); Infectious Diseases Society of America; American Society of Blood and Marrow Transplantation (2001) Summary of the guidelines for preventing opportunistic infections among hematopoietic stem cell transplant recipients. Clin Infect Dis 33(2):139-144

36. Maertens J, Marchetti O, Herbrecht R, Cornely OA, Flückiger U, Frêre P, Gachot B, Heinz WJ, Lass-Flörl C, Ribaud P, Thiebaut A, Cordonnier C; Third European Conference on Infections in Leukemia (2011) European guidelines for antifungal management in leukemia and hematopoietic stem cell transplant recipients: summary of the ECIL 3-2009 update. Bone Marrow Transplant 46(5):709-718

37. Science M, Robinson PD, MacDonald T, Rassekh SR, Dupuis LL, Sung L (2014) Guideline for primary antifungal prophylaxis for pediatric patients with cancer or hematopoietic stem cell transplant recipients. Pediatr Blood Cancer 61(3):393-400

38. Cohen-Wolkowiez M, Moran C, Benjamin DK Jr, Smith PB (2009) Pediatric antifungal agents. Curr Opin Infect Dis 22(6):553-558
39. Lehrnbecher T, Attarbaschi A, Duerken M, Garbino J, Gruhn B, Kontny U, Lüer S, Phillips R, Scholz J, Wagner HJ, Wiesel T, Groll AH (2010) Posaconazole salvage treatment in paediatric patients: a multicentre survey. Eur J Clin Microbiol Infect Dis 29(8): 1043-1045

40. Cesaro S, Milano GM, Aversa F (2011) Retrospective survey on the off-label use of posaconazole in pediatric hematology patients. Eur J Clin Microbiol Infect Dis 30(4):595-596

41. Ananda-Rajah MR, Grigg A, Downey MT, Bajel A, Spelman T, Cheng A, Thursky KT, Vincent J, Slavin MA (2012) Comparative clinical effectiveness of prophylactic voriconazole/ posaconazole to fluconazole/itraconazole in patients with acute myeloid leukemia/myelodysplastic syndrome undergoing cytotoxic chemotherapy over a 12-year period. Haematologica 97(3): 459-463

42. Tucker RM, Haq Y, Denning DW, Stevens DA (1990) Adverse events associated with itraconazole in 189 patients on chronic therapy. J Antimicrob Chemother 26(4):561-566

43. Baxter CG, Marshall A, Roberts M, Felton TW, Denning DW (2011) Peripheral neuropathy in patients on long-term triazole antifungal therapy. J Antimicrob Chemother 66(9): 2136-2139

44. Novelli V, Holzel H (1999) Safety and tolerability of fluconazole in children. Antimicrob Agents Chemother 43(8):1955-1960 